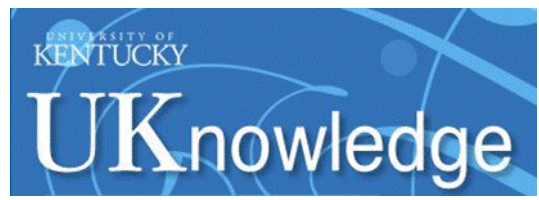

University of Kentucky

UKnowledge

$10-2018$

\title{
Real Time Operation of Smart Homes with PV and Battery Systems under Variable Electricity Rate Schedules and Transactive Power Flow
}

\author{
Huangjie Gong \\ University of Kentucky, huangjie.gong@uky.edu \\ Oluwaseun M. Akeyo \\ University of Kentucky, ochichikeyo@gmail.com \\ Vandana Rallabandi \\ University of Kentucky, vandana.rallabandi@uky.edu \\ Dan M. Ionel \\ University of Kentucky, dan.ionel@uky.edu
}

Follow this and additional works at: https://uknowledge.uky.edu/peik_facpub

Part of the Power and Energy Commons

Right click to open a feedback form in a new tab to let us know how this document benefits you.

\section{Repository Citation}

Gong, Huangjie; Akeyo, Oluwaseun M.; Rallabandi, Vandana; and Ionel, Dan M., "Real Time Operation of Smart Homes with PV and Battery Systems under Variable Electricity Rate Schedules and Transactive Power Flow" (2018). Power and Energy Institute of Kentucky Faculty Publications. 31.

https://uknowledge.uky.edu/peik_facpub/31

This Conference Proceeding is brought to you for free and open access by the Power and Energy Institute of Kentucky at UKnowledge. It has been accepted for inclusion in Power and Energy Institute of Kentucky Faculty Publications by an authorized administrator of UKnowledge. For more information, please contact UKnowledge@lsv.uky.edu. 


\title{
Real Time Operation of Smart Homes with PV and Battery Systems under Variable Electricity Rate Schedules and Transactive Power Flow
}

\author{
Digital Object Identifier (DOI) \\ https://doi.org/10.1109/ICRERA.2018.8566895

\section{Notes/Citation Information} \\ Published in 2018 7th International Conference on Renewable Energy Research and Applications \\ (ICRERA).
}

(c) 2018 IEEE Copyright Notice. "Personal use of this material is permitted. Permission from IEEE must be obtained for all other uses, in any current or future media, including reprinting/republishing this material for advertising or promotional purposes, creating new collective works, for resale or redistribution to servers or lists, or reuse of any copyrighted component of this work in other works."

The document available for download is the authors' manuscript version that is accepted for publication. The final published version is copyrighted by IEEE and available as: H. Gong, O. M. Akeyo, V. Rallabandi, and D. M. Ionel, "Real Time Operation of Smart Homes with PV and Battery Systems under Variable Electricity Rate Schedules and Transactive Power Flow," Rec. 2018 IEEE International Conferenceon Renewable Energy Research and Applications (ICRERA), Paris, France, pp. 1392-1395, doi: 10.1109/ ICRERA.2018.8566895. 


\title{
Real Time Operation of Smart Homes with PV and Battery Systems under Variable Electricity Rate Schedules and Transactive Power Flow
}

\author{
Huangjie Gong, Oluwaseun M. Akeyo, Vandana Rallabandi and Dan M. Ionel \\ Department of Electrical and Computer Engineering, University of Kentucky, Lexington, KY, US \\ huangjie.gong@uky.edu,m.akeyo@uky.edu,vandana.rallabandi@uky.edu, dan.ionel@uky.edu
}

\begin{abstract}
According to some utility schedules, the electricity rate is variable such that homes may be encouraged to buy and store power in a battery when it is inexpensive, and self-consume or sell to the grid during other times. Power arbitrage through a battery energy storage (BES), can help maintain consumer comfort and minimize residential electricity bills. This paper reports the calculated daily energy costs incurred by different types of homes for a given utility electricity rate schedule. The homes exchange power among each other behind a section of the distribution network. A free market system is formed and the electricity rate is a function of time, depending on the instantaneous supply and demand of power. A real time control for the BES based on its state of charge, residential power demand, and electricity rate is proposed. Relative savings in homes are achieved through rooftop solar photovoltaic systems, or BES, or both. It is shown that all types of houses benefit from the transactive power flow.
\end{abstract}

Keywords-Aggregator; Battery Energy Storage; Battery Control Scheme; Electricity Pricing; TOU rate; Smart Home.

\section{INTRODUCTION}

In recent years, residences with large installed capacity rooftop solar photovoltaic (PV) systems have become significant distributed energy resources. However, due to the unpredictability and high vulnerability to weather variation, PV systems have undesirable impacts on the power system especially when they are congregated, and their increasing penetration further exacerbates these issues [1], [2].

Solar PV systems typically produce their peak power at midday, and generally the maximum residential load occurs in the evening. This translates to an influx of power into the grid during the day, and large load demands in the evening, creating the undesirable typical "duck curve". This non uniform load behavior creates issues of distribution network overloading, and requires a highly flexible power system, which has cost implications for the utility company.

Methods of addressing the duck curve and associated challenges include load shifting, and addition of storage [3]-[6]. Time of use (TOU) rates aim to shift the load from peak to off-peak hours. Battery energy storage (BES) can additionally be used for arbitrage, leading to savings in the customer's electricity bill. Individual houses have different energy demands due to varying consumer habits, therefore, sharing power among homes, behind a section of the distribution network, achieves load shaving from the perspective of the grid, and the benefit to the customer is reduced electricity bills. In one study, it was found that community energy costs reduce by about $30 \%$ for a moderate level of PV penetration [7]. Peer to peer power trading, or transactive power flow is facilitated by an aggregator which provides a platform to distribute energy among different houses according to the willingness of the houses to buy or sell energy at a certain time point [8], [9].

This paper proposes a district system with different types of homes and an aggregator. The considered cases include homes with solar PV resources but no BES, and homes which feature both solar panels and BES. Also included are homes with only BES, and conventional residences with no solar PV generation or BES. Twelve houses in total are considered, and instantaneous load profiles are calculated by BEopt and EnergyPlus. A real time BES control scheme is proposed for home energy balance. The daily energy costs for four different types of homes on two representative days in summer and winter are evaluated.

\section{Transactive Power Flow}

Power flow between the houses behind a section of the distribution network is facilitated by the aggregator (Fig. 1). The bidding scheme, which defines the relationship between the energy bought and its rate for each house is received at the aggregator and it decides the real time rate and energy distribution.

The bidding scheme for each home is represented by a straight line, as follows,

$$
E_{i}=a_{i} \cdot r_{i}+b_{i}, \quad i=1,2, \ldots, n,
$$

where $E_{i}$, the energy assigned to house $i ; r_{i}$, the electricity rate; $a_{i}$ and $b_{i}$ are coefficients.

Behind the aggregated sectional distribution network, the net energy assigned to all the houses is set to zero to ensure transactive power flow, therefore,

$$
\sum_{i=1}^{n} E_{i}=0
$$

The electricity rate at one instant of time, $r$, which is equal for all houses, is decided by solving (1) and (2) as follows,

$$
r=-\frac{\sum b_{i}}{\sum a_{i}}, \quad i=1,2, \ldots, n, \quad r_{b}<r<r_{s}
$$




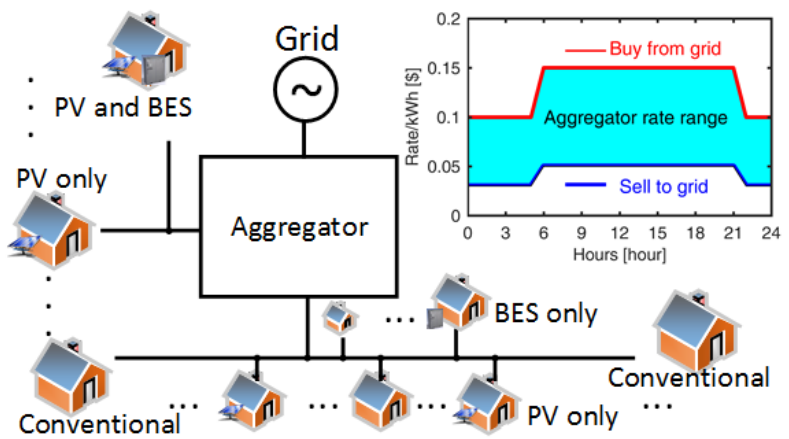

Figure 1. Schematic representation of the proposed grid distribution and aggregator scheme. All houses participate in the aggregation, which is responsible for deciding the electricity rate and power distribution according to the bidding schemes. Four types of houses, namely, conventional houses without BES and PV, houses having BES only, houses having PV only, and houses with both BES and PV, are considered.

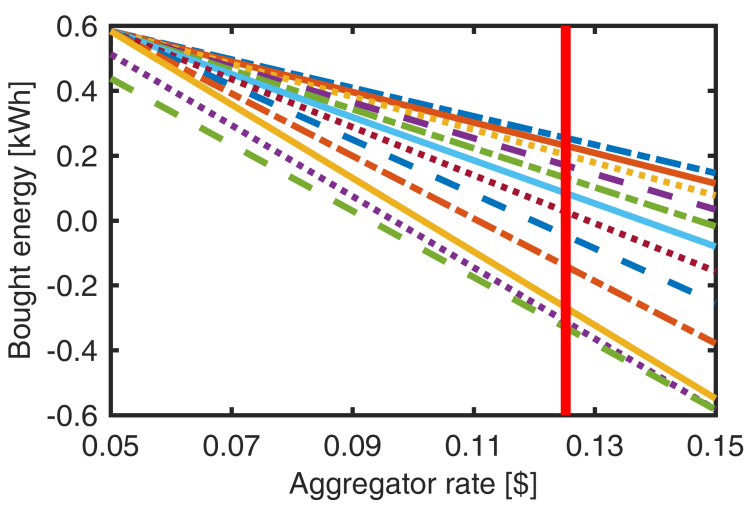

Figure 2. Aggregator decision of electricity rate and energy distribution based on instantaneous bidding schemes, represented by a line for each of the 12 houses. The electricity rate at the aggregator is such that the total sold energy is equal to the bought energy, as illustrated by the bold line. At this time, the rate is $\$ 0.125$.

where $r_{b}$ and $r_{s}$ are the rates offered by the grid to the houses for buying and selling electricity, respectively. It is worth noting that solving (1) and (2) might result in a rate lower than $r_{b}$ or higher than $r_{s}$. The houses will trade power directly with the grid under such circumstances, and therefore the rate decided by the aggregator is bounded by $r_{b}$ and $r_{s}$.

The energy assignment among houses is decided by substituting the rate decided by the aggregator from (3) in (1) (Fig. 2).

\section{Home Energy MANAGEMEnt}

The bidding scheme for each house depends on the SOC of the BES (Fig. 3). It is observed that for lower SOCs at the same price, the house is more likely to buy power. At the same battery SOC, homes shift from buying to selling power as the electricity rate increases. In two extreme situations when SOC is $0 \%$ or $100 \%$, homes only buy or sell power regardless of the price.

In this case, the maximum energy bought from the aggregator is limited to $0.58 \mathrm{kWh}$ for each time step assuming

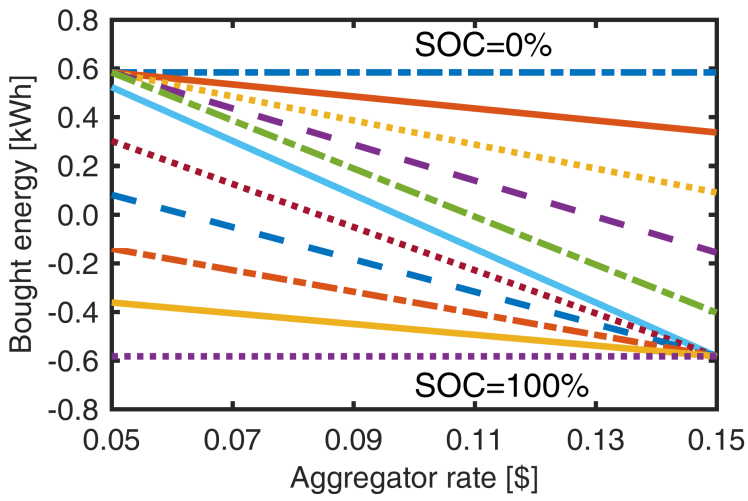

Figure 3. Bidding schemes of the same house under different SOCs of the BES. The SOCs increase from top to bottom. The energy bought depends on the rate at the aggregator, except for the two extreme situations when the battery $\mathrm{SOC}$ is at the minimum or maximum, in this case, $0 \%$ or $100 \%$.

the maximum BES power is $7 \mathrm{~kW}$ and the simulation step, 5 minutes.

The home energy management (HEM) system decides the BES power and energy from the grid at each time step from three real time estimations (Fig. 4). In the first, the BES power is calculated from the PV generation, house load, and aggregator power. The power balance for each house gives,

$$
P_{P V}(t)+P_{B E S}(t)+P_{G}(t)+P_{A}(t)=P_{H}(t),
$$

where $P_{P V}(t)$, the PV generation; $P_{B E S}(t)$, BES power; $P_{G}(t)$, power from the grid; $P_{A}(t)$, power from the aggregator; $P_{H}(t)$, home load demand.

In the second estimation, the BES power is limited to its maximum and in the third, the available amount of BES energy is defined as:

$$
\left.E_{B E S}\right|_{t}=\left.E_{B E S}\right|_{t-1}+P_{B E S}(t) \cdot \Delta t .
$$

If the BES power or the available energy cannot meet the requirements imposed by power balance, the house needs to buy deficit energy from the grid. The total energy cost for each house within a specified time interval is the sum of the cost of buying from the aggregator and grid, as follows:

$$
p(t)=\left.E_{A}\right|_{t} \cdot r(t)+\left.E_{G}\right|_{t} \cdot r_{G}(t),
$$

where $p(t)$, the electricity price; $E_{A}$, the energy bought from the aggregator; $r(t)$, aggregator rate acquired from (3); $E_{G}$, energy bought from the grid; $r_{G}(t)$, grid rate, which is $r_{s}$ and $r_{b}$ when the grid is selling and buying, respectively. At the end of the day, the energy stored in the BES is sold to the grid at the rate $r_{b}$, and therefore, the daily cost, $p_{T}$ is,

$$
p_{T}=\sum_{t=1}^{t_{\max }} p(t)-\left.E_{B E S}\right|_{t_{\max }} \cdot r_{b}\left(t_{\max }\right),
$$

\section{CASe Study}

A neighborhood comprising 12-houses is analyzed and four different houses types, namely, conventional residences which have no solar PV and BES; homes with BES but no PV; 


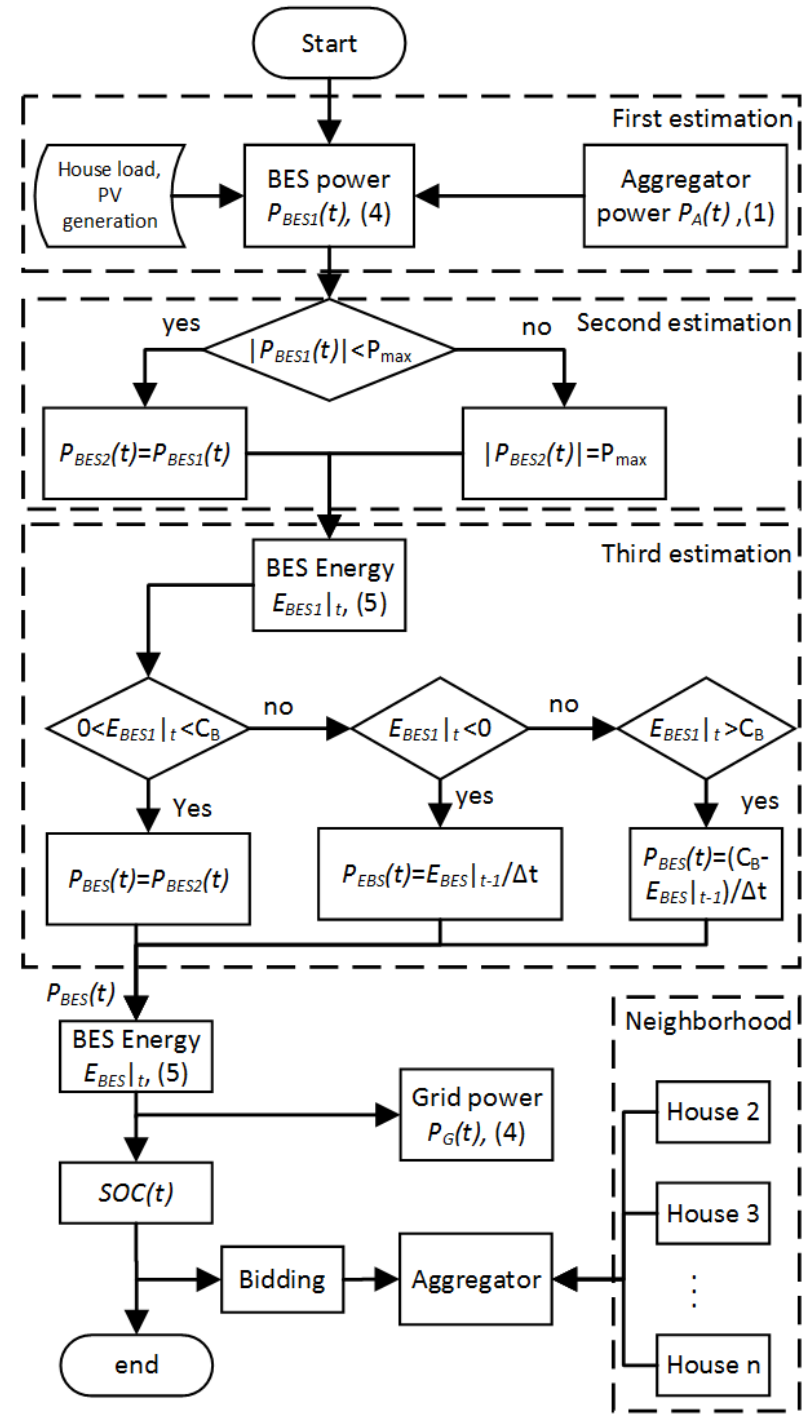

Figure 4. Flow chart for the proposed home energy management scheme. Three real time estimation stages are required to schedule the BES power. The bidding scheme and energy from the grid are decided at the end of each time step. The equations used for estimation is within the blocks in parentheses.

those with PV alone and those having both PV and BES are studied. The four types are referred to as 'Conventional', 'BES only', 'PV only', 'BES and PV', respectively. Each type has 3-different load profiles, denoted by $L_{1}, L_{2}, L_{3}$ for winter, and $L_{4}, L_{5}, L_{6}$ for summer (Fig. 5). The house loads are calculated from building models developed in BEopt and EnergyPlus, and the weather data is from Sacramento, CA. Houses 1, 4, 7, 10 have the load profile $L_{1}$ and $L_{4}$, houses $2,5,8,11, L_{2}$ and $L_{5}$, houses 3, 6, 9, 12 have $L_{3}$ and $L_{6}$ (Fig. 6(a), Fig. 7(a)). The PV rating is $10 \mathrm{~kW}$ and BES rating is $13.5 \mathrm{kWh} / 7 \mathrm{~kW}$, in line with those available from commercial manufactures. The initial BES energy is set to $50 \%$ of the capacity. The simulation time step is 5 minutes in this study.

All the houses consume net energy from the grid on the studied winter day (Fig. 6). The benefits of transactive power flow can be inferred from the fact that the total daily energy

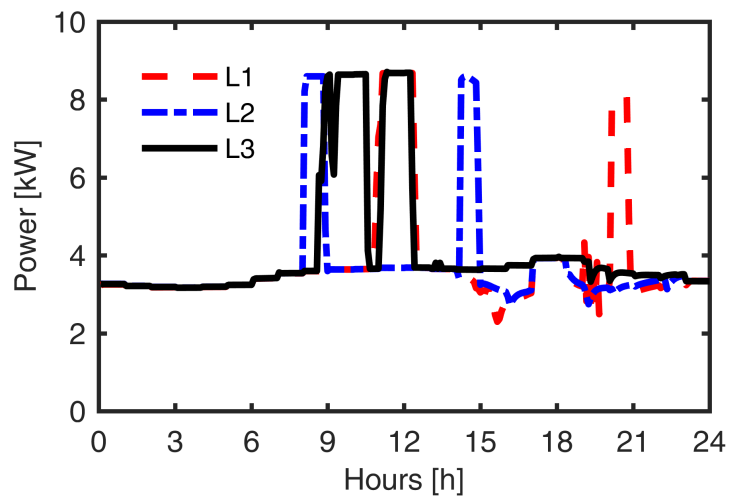

(a)

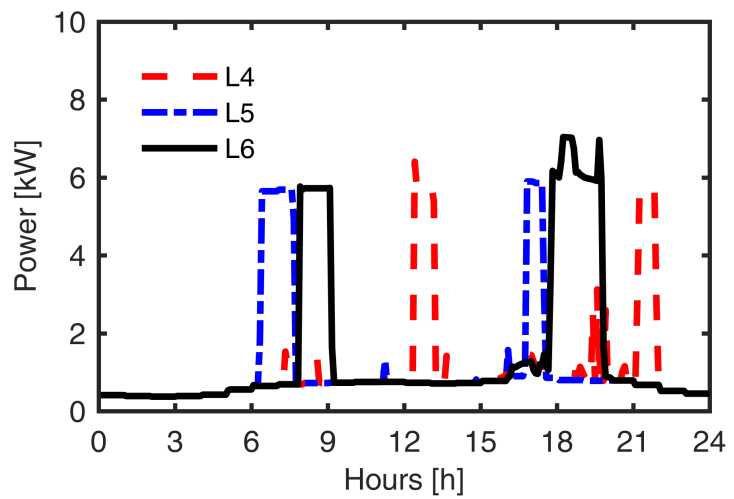

(b)

Figure 5. Different load profiles of the houses in (a) a winter day; (b) a summer day. The house loads are acquired from BEopt and EnergyPlus. The 'humps' in the profile are due to the operation of the electrical water heater.

cost is reduced by approximately $11 \%$. The 'BES only' type has the most energy cost reduction, of approximately $15 \%$. Other types, 'Conventional', 'PV only', 'BES and PV' reduce the daily energy cost by approximately $6 \%, 13 \%, 13 \%$, respectively.

On the studied summer day, houses with PV panels behave like generators and sell energy to the grid, and gain increased revenue with transactive power flow. An interesting finding is that homes with no PV generation, i.e. house types 'Conventional' and 'BES only' also have reduced daily energy costs due to power exchange between homes (Fig. 7). The houses selling electricity gain approximately $20 \%$ more and houses buying power spend around $30 \%$ less owing to the transactive power flow. The 'BES only' type reduces energy cost by $43 \%$, the highest improvement among all house types.

\section{CONClusion}

The paper studies a network including smart homes with rooftop PV and battery energy storage (BES). A real time BES control strategy is applied in each home in order to achieve energy balance and transactive power flow. The houses are allowed to trade the power within the network, thereby establishing a free market, in which the electricity rate is set by 


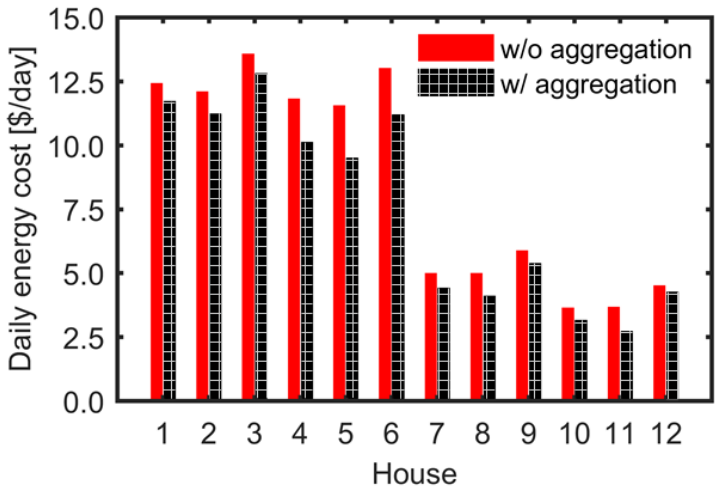

(a)

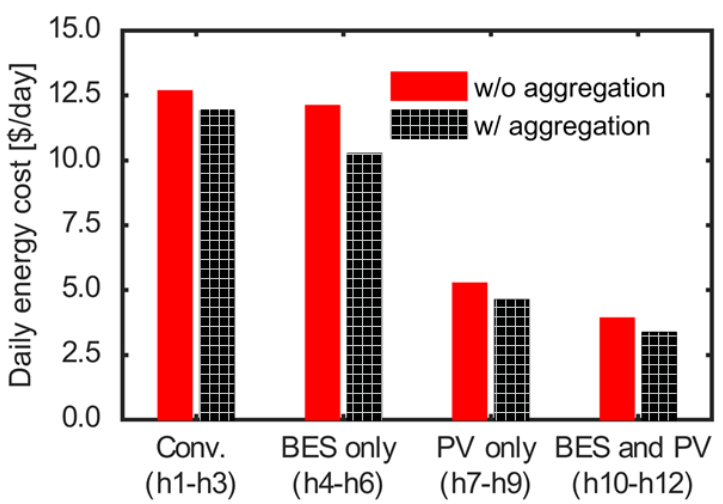

(b)

Figure 6. Daily energy cost in a winter day of (a) each house; (b) average of different house types. All houses connected to the aggregator have reduced energy costs. House type 'BES only' have the most cost reduction in the typical winter day.

instantaneous supply and demand. Four different house types were considered in this study, with three units in each category.

It is found that all different types of houses benefit from the transactive power flow for the PV and BES ratings considered in this study. For example, case studies with building load and weather data derived from BEopt and EnergyPlus show that for a representative winter day when all houses behave as consumers, the total daily energy cost is reduced by approximately $11 \%$ on an average. On a typical summer day, houses with a PV system have an additional $20 \%$ of earnings and houses without renewable sources save $30 \%$ of energy costs.

Houses equipped only with battery energy storage achieve the highest reduction of electricity costs up to $43 \%$ in the chosen summer day. The paper demonstrates benefits of transactive power flow, and energy storage at the consumer level, and advantages at the utility level include load shifting and peak reduction.

\section{ACKNOWLEDGMENT}

The support of University of Kentucky, the L. Stanley Pigman endowment, and Power and Energy Institute of Kentucky (PEIK) is gratefully acknowledged.

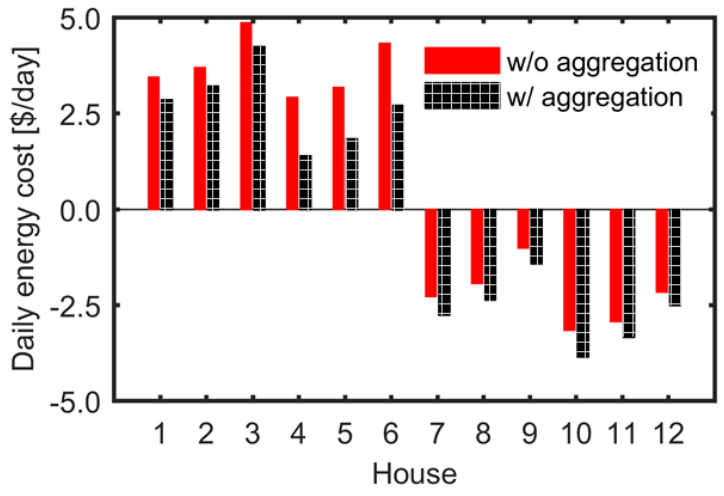

(a)

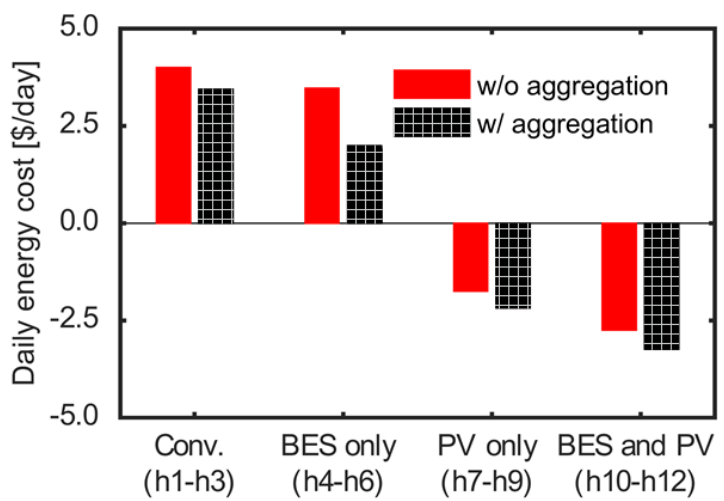

(b)

Figure 7. Daily energy cost in a summer day of (a) each house; (b) average of different house types. Houses having PV perform as generators in the summer day due to the high PV generation and relatively low load demands. Houses selling power have increased gains and houses buying power have reduced costs when they are all connected to the aggregator.

\section{REFERENCES}

[1] F. Blaabjerg and D. M. Ionel, Renewable Energy Devices and Systems with Simulations in MATLAB® and ANSYS®. CRC Press, Boca Raton, FL, 2017.

[2] P. Denholm, M. O'Connell, G. Brinkman, and J. Jorgenson, Overgeneration from solar energy in California: a field guide to the duck chart. National Renewable Energy Laboratory Golden, CO, 2015.

[3] P. Denholm, M. O'Connell, G. Brinkman, , and J. Jorgenson, "Overgeneration from solar energy in california: A field guide to the duck chart," 2015 .

[4] A. Ahmad and J. Y. Khan, "Roof-top stand-alone pv micro-grid: A joint real time bes management, load scheduling and energy procurement from a peaker generator," IEEE Transactions on Smart Grid, 2018.

[5] J. Weniger, T. Tjaden, and V. Quaschning, "Sizing of residential pv battery systems," Energy Procedia, vol. 46, pp. 78-87, 2014.

[6] E. O’Shaughnessy, D. Cutler, K. Ardani, and R. Margolis, "Solar plus: A review of the end-user economics of solar pv integration with storage and load control in residential buildings," Applied Energy, vol. 228, pp. 2165-2175, 2018.

[7] C. Long, J. Wu, C. Zhang, L. Thomas, M. Cheng, and N. Jenkins, "Peerto-peer energy trading in a community microgrid," in Power \& Energy Society General Meeting, 2017 IEEE. IEEE, 2017, pp. 1-5.

[8] B. Jiang and Y. Fei, "Smart home in smart microgrid: A cost-effective energy ecosystem with intelligent hierarchical agents," IEEE Transactions on Smart Grid, vol. 6, no. 1, pp. 3-13, 2015.

[9] J. Li, Z. Wu, S. Zhou, H. Fu, and X.-P. Zhang, "Aggregator service for pv and battery energy storage systems of residential building," CSEE Journal of Power and Energy Systems, vol. 1, no. 4, pp. 3-11, 2015. 